\title{
Essays
}

\section{Use of Animation in Teaching Cell Biology}

\author{
Bradley J. Stith* \\ University of Colorado at Denver, Biology Department, Denver, CO 80217
}

Submitted October 17, 2003; Revised April 16, 2004; Accepted April 19, 2004

Monitoring Editor: Jeffrey Hardin

\begin{abstract}
To address the different learning styles of students, and because students can access animation from off-campus computers, the use of digital animation in teaching cell biology has become increasingly popular. Sample processes from cell biology that are more clearly presented in animation than in static illustrations are identified. The value of animation is evaluated on whether the process being taught involves motion, cellular location, or sequential order of numerous events. Computer programs for developing animation and animations associated with cell biology textbooks are reviewed, and links to specific examples of animation are given. Finally, future teaching tools for all fields of biology will increasingly benefit from an expansion of animation to the use of simulation. One purpose of this review is to encourage the widespread use of animations in biology teaching by discussing the nature of digital animation.
\end{abstract}

Keywords: learning, biology education, computer-aided instruction, animation, simulation.

\section{INTRODUCTION}

Although video microscopy has long been used as a valuable teaching tool (see C.D. Watters' "Video Views and Reviews" column in $\mathrm{CBE}$ ), the use of computer animation in teaching has recently expanded (as noted by the numerous animations now accompanying textbooks). Animation can have advantages over video microscopy, including simplification; unlimited resolution and magnification; ability to highlight certain symbols within a complex background; control of motion, shape, or color changes; and the stepwise fading in and out of symbols. Although this review centers on the teaching of cell biology, the discussion is readily applicable to the teaching of all fields of science.

\section{WHAT MAKES A GOOD ANIMATION?}

The value of animation may be evaluated by what appears in the animation and the technical aspects of the animation. In terms of what appears in the animation, in my opinion, less useful animations often oversimplify a concept or skip too many steps in a pathway. These less useful animations can be misleading in that they show a protein as one chain instead of multiple subunits (e.g., crucial for the understanding of the action of high molecular weight multimeric $G$ proteins after dissociation) or do not show growth factor receptor dimerization upon ligand binding. Even if the animation is

DOI: $10.1187 /$ cbe.03-10-0018

*E-mail address: bstith@carbon.cudenver.edu accurate, overly simple animation may not improve on a static illustration. Furthermore, as discussed later (see EVALUATION OF THE USE OF ANIMATION), animation of certain facts does not result in enhanced student understanding. Although my opinions are presented here, methods of evaluation of the value of an animation (based on rigorous testing in the classroom) are still needed.

In terms of technical aspects of animation, there are some general rules. For example, animation files should be of relatively small size, and the animation player should be commonly available for both Mac and PC platforms. If files are distributed by $C D$, the animation files can include sound and be very large (e.g., 15 megabytes). There is an advantage to small animation files (less than 50 kilobytes), however, because students, at home or on campus, can rapidly download them from the Internet. Thus, the animation program should produce small files that can be viewed with a player that is typically found in the Web browser. The animation player should be of small size and seamlessly incorporated into the browser (such as Macromedia's players, described later).

The animation should include some interactivity through the use of hot keys (see "NEXT" key in Figure 1). The student can click on a hot key on the animation stage to produce an action or make a choice (clicking on the hot key can produce a jump to a different animation to explain one part of the current illustration, replay the current animation, or, when the student is ready, proceed to the next animation). The animation program should also be able to produce "rollover" controls-for example, as the mouse-controlled cursor is 


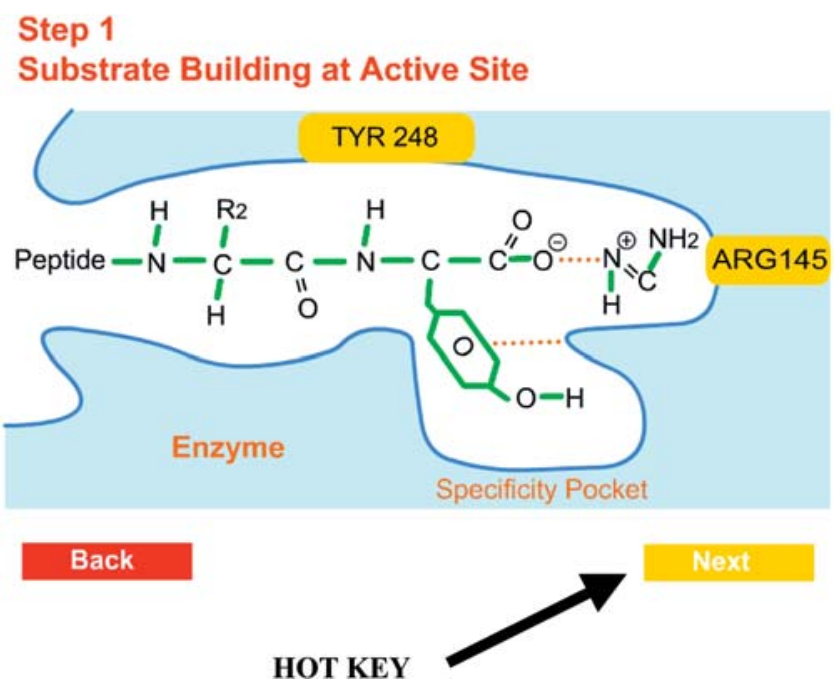

Figure 1. Animation of enzyme-substrate binding (http://carbon. cudenver.edu/ bstith/Lam\%20animation.swf).

placed over a symbol, the symbol changes shape to highlight the command line. A rollover could also function so that when a student points the cursor at an item on the screensay, a protein - the name of the protein pops up. Thus, the names of the various cell parts or proteins do not clutter the illustration.

Another suggestion is that the animation be scalable. This means that the animation can be enlarged (without image degradation) for use in large lecture halls (or decreased in size for smaller computer monitors). Animation that uses vector-based images generates shapes through mathematical equations; these images can be enlarged or reduced without image degradation. The file for these images will also be small. In contrast, bitmapped images are produced by a series of individual color dots. As a bitmapped image is enlarged, it will degrade. Bitmapped images also typically require larger file sizes than vector-based images.

\section{TOOLS FOR CREATING ANIMATIONS}

Macromedia's FLASH (http://www.macromedia.com/ software/flash/) is one program that meets all these requirements (view cell biology examples at http://carbon.cudenver. edu/ bstith/fert\%20wave.swf; http://www.cellbioed.org/ resources/resources.html; http://mama.uchsc.edu/vc/cancer/ welcome.cfm). In contrast, bitmapped animation (e.g., Macromedia's Director) cannot be enlarged or reduced (to see animations using Director: http://carbon.cudenver.edu/ $\sim$ bstith/fertiliz.htm and http://carbon.cudenver.edu/ bstith/ insulin.htm). The Shockwave player for Web browsers plays both FLASH and Director files and is free (http://sdc. shockwave.com/shockwave/download/download.cgi?\&P5_ Language=English). FLASH animation can be played on almost any operating system (Linux, Mac, Irix, Solaris, etc).

Even when FLASH images are enlarged, all image edges remain smooth (natural antialiasing). Shapes can be morphed automatically, and a shape can be "tweened" (i.e., after the animator enters the original and final position of a shape or symbol, the program calculates and produces intermediate locations). FLASH offers the ability to perform some calculations so simulation games are possible. FLASH can rapidly import a series of photomicrographs to produce a time-lapse movie (see the FLASH swf movie embedded in the following Web site: http://carbon.cudenver.edu/ bstith/ waverot.htm).

The animations produced with the program can also be published in gif, jpg, QuickTime, HTML, or stand-alone projector format. The program enables bandwidth profiling (where you can optimize animation for slower modems). Macromedia has also addressed concerns about accessibility for those with disabilities: http://www.macromedia.com/ macromedia/accessibility/gettingstarted/accessibility.html.

Because practical experience shows that FLASH has a steep learning curve, especially for sophisticated animations (e.g., one minute of animation may require 10 hours of work), one can hire a company (e.g., BioCreations; set up by Dr. M. Victor Lemas of the Department of Oncology at the Johns Hopkins Medical Institutes; http://www.biocreations. com/pages/bioanimations.html) or a computer science/art student to help develop scientific animations. However, SmartClips or ActionScripts within FLASH will design checkboxes or other interactive hot keys and allow the user to skip many programming steps.

FLASH can be packaged with Dreamweaver (Web authoring; competes against Microsoft's FrontPage) and Fireworks (Web graphics) as Macromedia's Studio MX.

Although similar in cost, Adobe's LiveMotion (http:// www.adobe.com/products/livemotion/main.html) is easier to learn because a lot of the scripting is already done. The product was discontinued in November of 2003 (although you can still purchase it), however; embedding of video is problematic and "tweening" is not possible, and support (books, Web sites, etc.) is less developed for LiveMotion. Animations from this program use the commonly available FLASH player. (For reviews, see http://www.iboost.com/ build/software/lm/ and http://www.pcreviewonline.com/ reviews/livemotion2/livemotion2.html.)

PowerPoint offers simple motion to introduce various players on the animation field and then cause them to dissolve at a proper time to introduce the next item in the illustration (http://www.e-learningcentre.co.uk/eclipse/ Resources/usingppt.htm). We have developed a PowerPoint slide that uses motion along hand-drawn pathways that can mimic the more powerful animation produced by FLASH (see our current research model for activation of phospholipase C during fertilization: http://carbon.cudenver.edu/ bstith/currentmodel.ppt; makes sure that you double-click twice to view the animation and that you use Internet Explorer, not Netscape). PowerPoint presentations and associated sound files can be converted into a "video" (using FLASH) or into standard HTML (do not use "Microsofthtml" because of compatibility problems) for the Web. FLASH animations can be imported into PowerPoint (follow procedures shown at http://www.macromedia.com/support/ FLASH/ts/documents/FLASH_powerpoint.htm) or by the use of Shyam's Toolbox for PowerPoint. The latter is relatively inexpensive, easy to use, and offers a free trial version (http://www.mvps.org/skp/toolbox/index.html).

QuickTime animations or movies are designated with the file extension "mov." Although Mac computers can play these "mov" files in PowerPoint, these animations cannot be 
incorporated into PowerPoint on a PC. Because PowerPoint on a PC can incorporate audio-video interleaved or "avi" files, one can convert the "mov" to "avi" files with QuickTime Pro (http://www.apple.com/QuickTime/ upgrade/).

Another type of animation is in the graphics interchange format (or "gif"; http://hotwired.lycos.com/webmonkey/ multimedia/animation/tutorials/tutorial1.html). These animations are more limited in their abilities than FLASH, are not scalable, and can produce very large files. However, gif animations are much easier to develop than those by FLASH, and Internet browsers do not require a player to view them. Dr. Donald Slish of State University of New York-Plattsburgh has discussed their use (Slish, 2000) and provides many useful examples (http://faculty.plattsburgh.edu/donald.slish/animations.html). In addition, Dr. Steve Berg of Winona State University maintains a large number of gif animations for cell biology (http://bio.winona.msus.edu/ berg/ANIMTNS/Directry.htm).

To develop gif animations, one could use software that is available free of charge, although the quality of these programs varies. Ulead sells a good, inexpensive program and offers a free trial (http://www.ulead.com/ga/runme.htm). Because of the value of the animation, the ease of development of gif animation, and the skills developed while teaching other students, some cell biology instructors have made development of a simple gif animation into a required exercise.

Note that I do not consider here the three-dimensional (3D) animation programs that require more in-depth computer knowledge and more powerful hardware, as well as added expense (for a review of these programs, see http:// www.bergen.org/AAST/ComputerAnimation/CompAn_ Tools.html). Often, these programs produce QuickTime animation files (extension: .mov).

Current reviews discussing the use of tools for animation in teaching are found in the online newsletter Online Learning News and Reviews (subscribe at http://www.vnulearning.com/ freeenews.htm and remember to search their archives for more information).

\section{ANIMATION RESOURCES FOR CELL BIOLOGY}

This review, like many courses, begins with a discussion of the animation of the molecular level.

\section{Interactive Animation of Biological Molecules}

Cell biology courses typically discuss protein structure and the induced fit model for enzyme action (i.e., the movement of various $\mathrm{R}$ groups of amino acids on the enzyme as the substrate binds). For animations on this topic, go to "III. More Specific Cell Biology Topics and Associated Web Sites, 4) Protein Structure Sites: Protein Folding (Chapt. 3) and Enzymes (Chapt. 6)" at http://carbon.cudenver.edu/ bstith/ cellbio.htm. It is difficult for static illustrations to portray this motion; however, programs such as Chime or Kinemage not only can show this motion but also can allow the student to rotate the protein to view the motion from different angles.

Due to problems with the required use of outdated browsers for Chime (discussed later in this article; see Animations Associated with Cell Biology Textbooks), I use Kinemage (short for "kinetic image"), or its Web version called MAGE, works on all computer platforms to visualize and rotate biological molecules. The user can rotate molecules by clicking on a molecule and then moving the mouse. As an example, animation of the binding of substrate to carboxypeptidase A, which is accompanied by the large movement of amino acid side chains at the active site, can be found on the Web (http://kinemage.biochem.duke.edu/ javamage/java.html; also see figure 6-3 of Becker et al., 2003; and my FLASH animation at: http://carbon.cudenver.edu/ bstith/Lam\%20animation.swf; Figure 1).

The more powerful and commonly used program, Chime, also allows rotation of molecular models. A new version of Chime (2.6 SP4 for Windows) is available for download (http://www.mdlchime.com/downloads/downloadable/index.jsp). Cell Biology Education maintains a list of Chime images (http://www.cellbioed.org/resources/resources.html) and annotations explaining the structures that are particularly valuable. For Mac users, Chime requires OS9 ("Classic") and Netscape 4.78 with the Chime plug-in. Among many other sites, Berg (Winona State University) maintains a Web site with Chime illustrations that are of note to cell biologists (http://bio.winona.msus.edu/berg/tutorials. htm).

Other molecular visualization programs available include Cn3D (http://www.biosino.org/mirror/www.ncbi.nlm.nih. gov/Structure/cn3d/), Protein Explorer (http://molvis.sdsc. edu/protexpl/frntdoor.htm), and Jmol (http://jmol. sourceforge.net).

\section{Animation of Cellular Processes}

Certain processes in cell biology courses are more easily presented through the use of motion than with a static illustration. More specifically, animation clarifies those processes involving motion (the movement of polymerases along DNA or the ribosome along mRNA, for example).

The clutch model for cell extension (or filopodial protrusion) is difficult for students to understand. In this model (Mitchison and Kirschner, 1988, see p. 794 and figure 23-30 of Becker et al., 2003; Jay, 2000), G actin adds to the plus end of the microfilament ("plus end addition"), and this would push out the plasma membrane at the "leading edge of the cell." However, the plasma membrane is not pushed out as myosin pulls those microfilaments back from the leading edge of the cell (this is retrograde flow; Figure 2). When the membrane protein integrin binds the substrate under the cell (the extracellular matrix or ECM), forming a focal contact, the clutch is "engaged." The microfilament is locked into place by the focal contact, and myosin is unable to pull back the microfilament. Because plus end addition still occurs, when the clutch engages, the cell can then push out the plasma membrane. A FLASH animation of this clutch model is located at: http://carbon.cudenver.edu/ bstith/ cellcrawling.swf.

I have found that many students are confused about the process of freeze-fracture and how to interpret micrographs that result from this method. Questions arise concerning the meaning of the $\mathrm{P}$ and $\mathrm{E}$ face (for example, two common questions are the following: Are both the $\mathrm{E}$ and $\mathrm{P}$ face from the same cell? Why do membrane proteins typically occur in the $\mathrm{P}$ face, not the $\mathrm{E}$ face?). Working with an undergraduate student (Arthur Lam, a University of Colorado at Denver student in multimedia studies), we developed an animation of this process (http://carbon.cudenver.edu/ bstith/cell.swf). In lecture, I note that the membrane proteins are often 


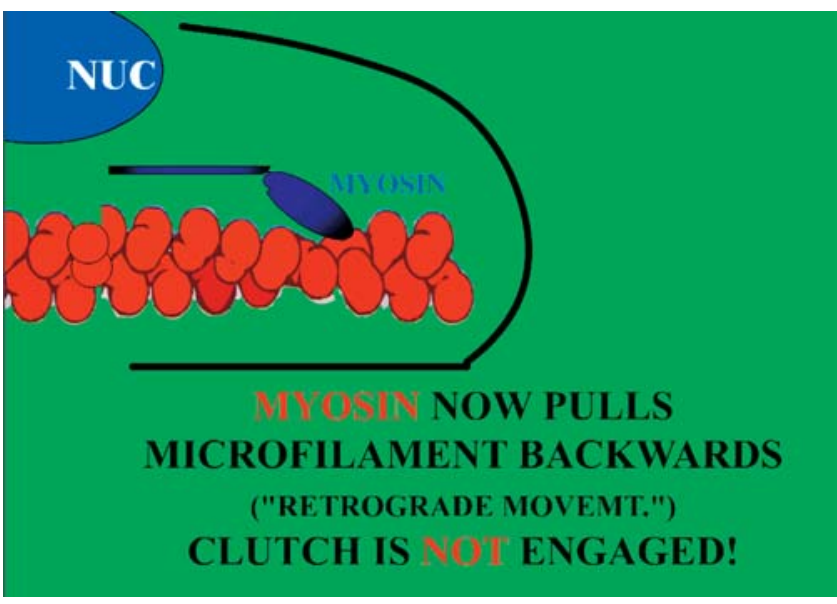

Figure 2. Animation of clutch model of cell movement (http:// carbon.cudenver.edu/ bstith/cellcrawling.swf).

anchored by cytoskeletal fibers so that they typically stay in the $\mathrm{P}$ face.

The development of the resting membrane potential is another difficult process to describe with static illustrations. Animations can show the direction and changing size of the chemical and electrical driving forces as potassium equilibrates across the plasma membrane to produce a negative resting potential (see "III. More Specific Cell Biology Topics and Associated Web Sites: (5) Membrane Transport Chapters: Membrane Potential" at http://carbon.cudenver.edu/ bstith/cellbio.htm).

Cell signaling cascades are typically presented in static illustrations as one overwhelming series of inhibitory and stimulatory steps. Animation can introduce each step individually and in order to emphasize multiple effects of one protein and the cellular location of each effect. The Web page "Signal Transduction Knowledge Environment" (http:// stke.sciencemag.org/resources/education/) offers, with a subscription, a literature background and animations on heterotrimeric $G$ proteins, receptor tyrosine kinases, Notch pathway, exocytosis, the acetylcholine receptor, and the action of $\mathrm{SH} 3$ domains.

The ability to introduce each step independently reduces the clutter of static illustrations in which all steps are shown at once. Phosphate can be shown being added to a protein, and subsequent activation or inactivation of the protein can be highlighted by creative symbols (e.g., sparks or glowing colors to indicate activation). In addition, spatial relationships can be described: multiple map kinase proteins can be activated in the cytoplasm by phosphorylation, then some of the map kinase molecules would phosphorylate a substrate in the cytoplasm, whereas others can move across the nuclear envelope to regulate transcription factors in the nucleus.

Cell signaling paths with inhibitory steps are the most difficult to comprehend when presented as static illustrations. For example, the Wnt pathway begins with the extracellular ligand Wnt binding to its membrane receptor (frizzled) followed by activation of the receptor. The receptor in turn activates (shown by $\rightarrow$ ) the intracellular protein disheveled which then inhibits (==-1) glycogen synthase kinase 3 (GSK-3). Once GSK-3 is inhibited, it can no longer induce the destruction of beta-catenin. Often, this path is represented as follows:

Wnt $\rightarrow$ Frizzled $\rightarrow$ Disheveled $===\mid$ GSK-3 ==-|Beta-catenin.

Students often incorrectly interpret this static display of the cascade to mean that the presence of Wnt leads to inhibition of beta-catenin. Similar problems arise with the hedgehog pathway (hedgehog $===\mid$ patched $===$ smoothened) or apoptosis (EGL-1 ==-ACED-9 ==-ACED-4). Use of animation can correct misinterpretation of these pathways: for example, click on "Movies" on the title bar of Dr. Randall Moon's home page for animations on the Wnt pathway: http:// faculty.washington.edu/rtmoon/).

Animations often depict hypothetical models based on current research. For example, an animation showing the possible role of phosphatidic acid in sperm-egg membrane fusion and activation of phospholipase $C$ in fertilization can be animated (see http://carbon.cudenver.edu/ bstith/ fert\%20wave.swf). This animation not only summarizes current work to new students working in my lab, but also provides a conceptual model on which future experiments may be designed.

One problem with teaching biology is that our current understanding of many cellular pathways is incomplete or wrong. Thus, an animation may include hypothetical events that are not proven to occur in the pathway. As our knowledge expands with new publications, animation of a pathway may be proven incorrect. Authors should note when hypothetical involvement of proteins is involved, use black boxes for unknown steps, or note whether the exact order of events has been proven. Animations should represent our best current model and be continually updated.

\section{Animations Associated with Cell Biology Textbooks}

Molecular Cell Biology. Like animations accompanying other texts, the CD that accompanies Molecular Cell Biology (Lodish et al., 2003) contains many valuable animations. Although animation 14.1 on protein sorting is too simple, animation $17.4 / 5$ on synthesis and secretion of proteins is well done. Animations from chapter 18 on microfilaments, cell cycle animation number 34.4, and the apoptosis animation (chap. 22 or 23 depending on edition), are also very good.

In addition, this $\mathrm{CD}$ has many unique animations of cell biology methods, but there is one animation that, in my opinion, represents the dramatic power of good animation of a difficult topic. The development of segmentation in the Drosophila embryo is animated from gradients of morphogens and transcription factors to the final adult fly structure (see "Gene Control of Embryonic Development," section 14.30).

Molecular Biology of the Cell. The fourth edition of Molecular Biology of the Cell (Alberts et al., 2002) is associated with a CD (Walter et al., 2002) with 21 animations in QuickTime (mov) format. The CD includes a 65-page viewing guide and 36-page teaching guide by K.K. Bernd. The latter, devoted to helping instructors integrate animations and video on the CD into the lecture course, is especially helpful. 
The CD includes valuable Chime animations of the changes in protein structure induced by substrate (aspartate transcarbamylase; see molecular model 3.9) or by guanosine triphosphate (GTP) (elongation factor Tu [EF-TU]; see molecular model 3.10) or by calcium binding (calmodulin; see molecular model 15.9). The CD installs an older version of Chime and Netscape Communicator 4.7, however, which cannot view illustrations requiring the newer version of Chime (e.g., Cell Biology Education electronic resources Web site).

The World of the Cell. The undergraduate text The World of the Cell (Becker et al., 2003) has more than 30 animations (many with sound) and interactive activities (presented on a CD or from http://www.thecellplace.com). Although some animations are oversimplified, there are many excellent animations on basic cell processes. For example, one interactive animation allows students to click on various receptor types ( $\mathrm{G}$ protein-linked or tyrosine kinase) located in one plasma membrane to activate different signaling paths within the cell.

Cell Biology. Pollard and Earnshaw's (2002a) Cell Biology is associated with a CD titled Electronic Image Collection for Cell Biology (Pollard and Earnshaw, 2002b) that has some 15 animations on an associated CD. The FLASH animations (swf files) are detailed and highlight molecular movement (e.g., the ligands do not simply move straight toward each other but bind after random motion). When the animations are played separately from the associated program, these animations can be enlarged for the lecture hall.

The Cell: A Molecular Approach. The CD associated with The Cell: A Molecular Approach (Cooper and Hausman, 2004) has more than 100 narrated animations. The animations are on a special edition of a stand-alone CD (Purves et al., 2003). The animations are 1 to 34 megabyte QuickTime ("mov") files. The 3D computer animations are sophisticated (there are especially clear animation of mitosis, meiosis, transcription, translation, and the humoral immune response), and the simple animations are humorous and entertaining.

Cell and Molecular Biology. Karp's (2002) Cell and Molecular Biology has a CD titled CellView (Keefer, 2002). The images are small, must be used within the program itself, and cannot be used separately in a large lecture hall (similar to HyperCell described later). There are about 18 animations (e.g., G protein coupling is the animation for the cell signaling chapter).

\section{Animation Not Associated with a Text}

Animations of inositol 4,5-trisphosphate and intracellular calcium release (Figure 3), immunological topics, and reverse transcriptase polymerase chain reaction are in the collection hosted by Cell Biology Education (http://www.cellbioed.org/ resources/resources.html\#flash). Developed by Malcolm Campbell of Davidson College, these animations emphasize the use of hot keys so that the students can step through animations or even back up to progress at their own rate.

A stand-alone CD (or VHS tape), SciRen Biology (Taggart, 1997) is not associated with a text. It features excellent 3D computer animations. The clear animations cover many cell biology topics including DNA replication, transcription, the lac operon, mitosis, active transport, and cell respiration. Because the program that opens the movies is not compatible with Windows 2000 or later versions, the 32 animations (.mpg files ranging from 3 to 30 megabytes) must be viewed

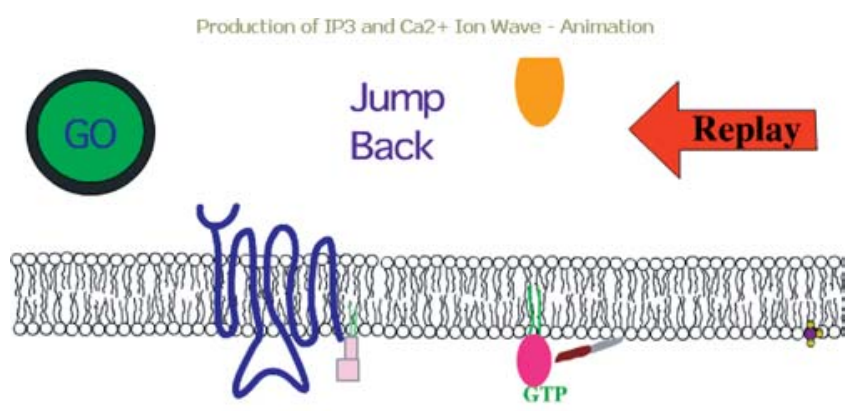

$\mathrm{Ga}$ has been activated, released from the $/ /$ subunits, and drifted down the PM to interact with phospholipase C- $\gamma(\mathrm{PLC}-\gamma)$. PLC glides down to cleave $\mathrm{PIP}_{2}$ which is embedded in the PM.

Figure 3. Animation of inositol 4,5-trisphosphate (IP3) production and action (http://www.cellbioed.org/resources/flash/IP3.html).

separately with Windows Media Player but are suitable for large lecture halls.

The most comprehensive (if out-of-date) set of animations at present is HyperCELL '98 (Williams, 1997). There are about 275 animations (in dxr, or Macromedia Director files) that cover the entire range of cell processes. This CD was packaged with an earlier edition of The Molecular Biology of the Cell. Possession of this CD, although it is dated and contains errors, should be required of any instructor of cell biology. The animation, however, is too small (and cannot be enlarged) to use in large lecture halls, and the various animations cannot be used independently of the program (i.e., you must exit your PowerPoint lecture, start the HyperCell '98 program, then go through more steps to view a particular animation). I hope that an update or similar complete set of scalable animations that can be presented in lecture independently of the HyperCell program will be produced in the near future.

\section{EVALUATION OF THE USE OF ANIMATION}

Because students learn through various methods (auditory, visual, and kinetic; http://trc.ucdavis.edu/msjacob/partners/ 25_learning.htm; Kearsley, 1996), the use of animation and associated sounds may present the concept more effectively than static illustrations or reading of text. For example, short sound effects (e.g., a squeak) or words can be used to highlight certain motions or steps in an animation (although the use of voiceover can increase the animation file size tremendously). The benefit of animation to a visual learner is more obvious, but even kinetic learners may be more involved in learning because they must use their mouse to control the animation. The digital animations can be used in the classroom and then made available on the Web or a CD, so that students can access these learning tools at home, in the dorm, at their job, or while traveling. Thus, there may be more long-term benefits to the use of animation that would be difficult to quantify.

Studies demonstrating the value of animation over static illustrations in science teaching are rare. One study examined 
the use of animation in the teaching of chemical concepts (Williamson and Abraham, 1995). Compared with students in lecture sections that received the same lecture material without the supplemental animation, students in sections that viewed a series of 1- to 2-min animations had significantly higher exam scores (on different exams, increasing from an average score of $59 \%-70 \%$ or $50 \%-$ $63 \%$ ). The animations increased lecture time by only $3 \%-6 \%$, and the authors suggested that this increase did not play a role in the elevated exam averages. In addition, student "contentment" was higher in the section that viewed the animations.

Although I have not been able to find data supporting the value of animation in teaching biology, I offer the following simple study. Note that this is merely a beginning; more thorough studies conducted over multiple semesters are needed.

To collect these data, I presented a $\sim 1-h$ lecture (29 PowerPoint slides) on apoptosis (http://carbon.cudenver. edu/ bstith/apoptosiscellB_files/frame.htm). The lecture emphasized static illustrations of apoptosis and ended with a four-slide explanation of the path to apoptosis that involves cytochrome $\mathrm{C}$ movement from the mitochondrion. This apoptosis path was discussed in slides 25-28 and required $\sim 18 \mathrm{~min}$ of the 60 -min lecture.

At the end of the lecture, without prior warning, I asked 27 students to leave their notes and books and go to the hallway. These students were seated to the left of an imaginary line drawn down the middle of the lecture hall (front to back). Because many of the better students sit in the front rows, this line would evenly divide these students.

To the remaining 31 students, I showed a brief, 65-sec animation illustrating the path to apoptosis involving the mitochondrion. I showed it three times, requiring less than 4 min. The other students then returned to the lecture hall, I passed out a question sheet, and the whole class took the quiz.

The animation showed a trophic factor bound to its receptor and subsequent phosphorylation and inactivation of BAD. BCL-2 continued to inhibit apoptosis. The animation then showed events leading to apoptosis in the absence of trophic factor: BAD movement to the mitochondria surface to inhibit BCL-2, release of cytochrome $\mathrm{C}$ from the mitochondria, cytochrome $\mathrm{C}$ binding to APAF-1, and subsequent activation of caspase 9 and 3 . The animation was titled "Apoptosis" and was on the CD-ROM associated with the textbook Molecular Cell Biology (to view the animation, go to http://bcs.whfreeman.com/lodish5e/ and go to chap. 22).

The animation emphasizes the order of events, the motion of BAD from the cytoplasm to the mitochondrial membrane, the physical addition of phosphate to BAD by an activated trophic factor receptor, the location of BCL-2 in the outer mitochondrial membrane, the movement of cytochrome $\mathrm{C}$ from the mitochondrion to the cytoplasm, the binding of cytochrome C to APAF-1, and, finally, the sequential partial proteolysis and activation of procaspases 9 and 3. As noted earlier, these events were also described in the PowerPoint lecture given to all students in slides 25-28.

The quiz consisted of 11 questions relating to whether the student saw the animation of this pathway to apoptosis (Appendix 1). (Question 1 was not graded but merely
Table 1. Correct answers on apoptosis quiz

\begin{tabular}{rcr} 
Question & $\begin{array}{l}\text { No animation } \\
\text { (\% of 27 students) }\end{array}$ & $\begin{array}{l}\text { Viewed animation } \\
\text { (\% of 31 students) }\end{array}$ \\
\hline & & \\
3 & 74 & 74 \\
4 & 78 & 87 \\
5 & 70 & 90 \\
6 & 81 & 100 \\
7 & 89 & 68 \\
8 & 56 & 94 \\
9 & 78 & 87 \\
10 & 63 & 90 \\
11 & 56 & 74 \\
\hline
\end{tabular}

identified in which of the two groups the student had been assigned.)

For questions 2-11, the overall average of students who did not see the animation was $70.0 \% \pm 3.5 \%$ (average \pm s.e.m.; $n=27$ students) whereas the average for those who did see the animation was $84.2 \% \pm 3.2 \%(n=31)$. The percentages of correct answers to the last 10 questions are in Table 1.

Using a two-tailed unpaired $t$-test, the viewing of the animation significantly increased the scores by 14 percentage points $(P<0.0097)$. The standard deviations of the two groups passed an $F$ test for equivalent standard deviations in both groups, and the data passed the assumption test for Gaussian distribution (GraphPad InStat; San Diego, CA).

The overall effect of BCL-2 on apoptosis was emphasized on questions 2 and 6, and the use of the animation did not increase the scores on these two questions. The PowerPoint lecture that all students viewed emphasized that BCL-2 was an inhibitor of apoptosis. I noted that artificial inactivation of BCL-2 in cancer cells would kill cancer cells and might be a treatment for cancer (see slide 22). I also discussed how artificial activation of BCL-2 might slow the aging process wherein one looses muscle and brain cells over time.

One might suggest that this discussion and definition of BCL-2 action was not reinforced by the use of the animation. Similar results were obtained in the more complete study of the effect of chemistry animations; questions that were not directly addressed or enhanced by animation did not have higher correct answers in the student group that viewed the animations (Williamson and Abraham, 1995).

The other eight questions on the apoptosis quiz, however, can be construed as emphasizing points that are depicted in the animation: motion of cytochrome $C$ (questions 3 and 4), the "last step" of the pathway (question 5), the action of phosphate addition to BAD (questions 7 and 11), movement of BAD over to the mitochondrion to inhibit BCL-2 (question 8), binding of cytochrome C to APAF-1 (question 9), and the physical location of BCL-2 (question 10). The average score on these questions (excluding questions 1, 2, and 6) was $68.1 \% \pm 3.6 \%$ for those who did not see the animation and $87.9 \% \pm 2.8 \%$ for those who did. The viewing of the animation increased the correct answers for these questions by $\sim 20$ points $(P<0.0006)$.

Although one could ascribe the results to the fact that students who viewed the animation studied the material for 
$22 \mathrm{~min}$ instead of $18 \mathrm{~min}$, these data suggest that questions based on definition (BCL-2 inhibits apoptosis) are not enhanced by animation but that questions involving order or location of events are.

\section{ANIMATION AND THE FUTURE OF CELL BIOLOGY EDUCATION}

The Pew Internet and Life Project has quantified the time spent by students on interactive computer or online games and notes that many students play computer or online games as a way to postpone studying (http://www.pewinternet.org/ reports/toc.asp?Report=93). The increasing importance of computer or online gaming in our culture (e.g., large amount of time spent in these activities; that television sets will integrate computer games and Web access) is discussed at http://www.game-culture.com/. Marinelli and Pausch (2004 p. B16) suggested that the development of the power of video gaming in education ("edutainment," interactive or simulation-based games) will cause a revolution in education equivalent to the introduction of mass-produced textbooks. Video games can teach "a general way of thinking about problem solving" through student "attempts to find a sequence of actions that will overcome a set of obstacles, solving subsidiary problems during that process." Instructors' inexperience with (or reluctance to use) this educational tool and the high cost and extensive time required for effective video games may be overcome within the next 10 years.

One educator, Clark Aldrich (2003), has separated video gaming into three categories:

1. Game-Based Simulations: Using a popular game model (e.g., Wheel of Fortune), the game asks students questions related to class topics.

2. Story-Based Simulations: While reading a story, the student makes choices that lead to different paths, and the outcome of the decision is presented graphically.

3. Virtual Product/Lab Simulations: Here the student can actually see lab equipment and manipulate it to obtain data.

Although there are many simulation programs for subjects such as cardiovascular physiology (e.g., http://www.webcom.com/medmult/welcome.html), there are simulation programs that might be of interest to cell biologists-for example, cancer biology (Bockholt et al., 2003; http:// www.cellbioed.org/articles/vol2no1/article.cfm? ArticleID=46), "Neurosim" (http://www.st-andrews.ac.uk/ $\sim$ wjh/neurosim/contents.htm), and NERVE (http://pb010. anes.ucla.edu/). In these programs, the student provides input, and the program then provides graphic output of the response.

Future simulations may involve the students altering 3D protein structure to change enzyme activity (altering $\mathrm{Km}$, $\mathrm{Vm}$, etc.). The entire cell may be modeled in a program, and a student may increase (or decrease) microfilament stability and view altered cell movement and other effects.

In short, computer simulation games are currently a major part of student life, and one can only predict that their impact will increase further. Thus, as instructors are increasing their use of animation in lectures, cell biology education will also increase the use of interactive simulation games.

\section{SUMMARY}

This essay argues that lectures using animation lead to more complete understanding of certain cell biology concepts than lectures that use only static illustrations. Characteristics of good animation and an evaluation of the value of animation were reviewed. Cell biology topics that would benefit the most from animation would involve sequential steps in a pathway motion or physical modification of a protein.

The use of animation and simulation will have an increasing impact on our teaching. All faculty are encouraged to develop their own or search the Web and CD-ROMs associated with textbooks to find those animations that directly relate to topics they emphasize in the lecture. To make these tools available to students, faculty are also encouraged to make the animation (or link) available on the course Web site. It is also recommended that animation be made freely available to all faculty.

\section{ACKNOWLEDGMENTS}

The National Science Foundation (grant IBN 0110609) provided support for development of animations related research.

\section{REFERENCES}

Alberts, B., Johnson, A., Lewis, J., Raff, M., Roberts, K., and Walter, P. (2002). Molecular Biology of the Cell, New York: Garland Science.

Aldrich, C. (2003). Simulations and the Future of Learning: An Innovative (and Perhaps Revolutionary) Approach to e-Learning, San Francisco: Pfeiffer.

Becker W., Kleinsmith, L.J., and Hardin, J. (2003). The World of the Cell, San Francisco: Benjamin Cummings.

Bockholt, S.M., West, J.P., and Bollenbacher, W.E. (2003). Cancer cell biology: A student-centered instructional module exploring the use of multimedia to enrich interactive, constructivist learning of science. Cell Biol Edu. 2, 35-50.

Cooper, G.M., and Hausman, R.E. (2004). The cell: A molecular approach, Sunderland, MA: American Society for Microbiology Press and Sinauer Associates.

Jay, D.G. (2000). The clutch hypothesis revisited: Ascribing the roles of actin-associated proteins in filopodial protrusion in the nerve growth cone. J Neurobiol. 44, 114-125.

Karp, G. (2002). Cell and molecular biology: Concepts and experiments, New York: John Wiley and Sons.

Kearsley, G. (1996). Cognitive/Learning Styles, Washington, DC: George Washington University.

Keefer, D. (2002). CellView, New York: John Wiley and Sons.

Lodish, H., Berk, A., Zipursky, S.L., Matsudaira, P., Baltimore, D., and Darnell, J. (1999). Molecular Cell Biology, New York: W.H. Freeman.

Marinelli, D., and Pausch, R. (2004). Edutainment for the college classroom. Chron Higher Edu Chron Rev. 50 (March 19), B16.

Mitchison, T., and Kirschner, M. (1988). Cytoskeletal dynamics and nerve growth. Neuron 1, 761-772.

Pollard, T.D., and Earnshaw, W.C. (2002a). Cell Biology, Philadelphia: W.B. Saunders. 
Pollard, T.D., and Earnshaw, W.C. (2002b). Electronic Image Collection for Cell Biology, Philadelphia: W.B. Saunders

Purves, W.K., and the Mona Group. (2003). UNDERSTAND! Biology: Molecules, Cells and Genes, Sunderland, MA: American Society for Microbiology Press and Sinauer Associates.

Slish, D. F. (2000). Creating computer animations of biological concepts. Am Biol Teacher 62, 94-97.

Taggart, R. (1997). SciRen Biology [ISBN 157182751X], Plymouth, MI: Hayden-McNeil.

Walter, P., Theriot, J., and Morales, M. (2002). Cell Biology Interactive [ISBN: 0815338759], New York: Garland Science.

Williams, G. (1997). HyperCell '98, New York: Garland Science.

Williams, V.M., and Abraham, M.R. (1995). The effects of computer animation on the particulate mental models of college chemistry students. J Res Sci Teach. 32, 521-534.

\section{Appendix 1}

\section{QUESTIONS ON APOPTOSIS}

(Correct answer denoted by asterisk)

1. Did you view the animation?

A. True (yes, I viewed the animation)

B. False (no, I did not see the animation)

2. Which step is incorrect?

A. Trophic factor binds receptor and the receptor phosphorylates a protein.

B. The phosphorylated protein cannot inhibit a protein located in mitochondrial membrane.

${ }^{*}$ C. Active Bcl-2 stimulates apoptosis.

3. During apoptosis, one protein is released from the
A. smooth ER.
B. nucleus.
C. plasma membrane.
D. cytoplasm.
* E. mitochondria.

4. From question 3, the protein that is released is called

A. caspase 9 .

B. APAF.

* C. cytochrome C.
D. Bad.

E. caspase 3.

5. The "last step" of apoptosis is the activation of the enzyme that cuts up the cell

A. APAF.

B. cytochrome C.

* C. caspase 3.

D. Bcl-2.

E. caspase 9 .

6. When active, this protein normally prevents apoptosis

A. Bad.

B. APAF.

C. cytochrome C.

* D. Bcl-2.

E. caspase 3.

7. This protein is phosphorylated (and inactivated) by the trophic factor receptor

* A. Bad.

B. cytochrome C.

C. APAF

D. Bcl-2.

E. caspase 3 .

8. Active Bad inhibits

A. caspase 8 .

B. cytochrome C.

C. caspase 9 .

* D. Bcl-2.

E. caspase 3.

9. Cytochrome $\mathrm{C}$ binds to and stimulates

A. Bad.

* B. APAF-1.

C. trophic factor receptor.

D. Bcl-2.

E. caspase 3 .

10. Bcl-2 is located in the

A. plasma membrane.

* B. mitochondrial membrane.

C. lysosomal membrane.

D. nuclear envelope.

11. True or False*: In the absence of a trophic factor, bad is phosphorylated. 